\title{
Prevalence and roles of vice-chairs in schools and colleges of pharmacy
}

\author{
Joycelyn Yamzon ${ }^{1}$, David Q Pham², Karl Hess ${ }^{3}$ \\ ${ }^{1}$ Marshall B. Ketchum University College of Pharmacy, United States \\ ${ }^{2}$ Western University of Health Sciences College of Pharmacy, United States \\ ${ }^{3}$ Chapman University School of Pharmacy, United States
}

\section{Keywords}

Faculty mentorship

Faculty development

Vice chair

\section{Correspondence}

Joycelyn Yamzon

Marshall B. Ketchum

University College of Pharmacy

United States

jyamzon@ketchum.edu

\begin{abstract}
Introduction: The activities and roles of vice chairs (VC) in academic medicine are described in the literature but are not presently known in academic pharmacy. Aim: The objectives of this pilot study were to determine the prevalence of VC, describe the roles and responsibilities of VC in various departments, and evaluate why some institutions may not have VC.

Methods: A Qualtrics survey was sent to all pharmacy school Deans from October to November 2018. Survey results were analysed using qualitative and quantitative methods. Results: Based on the $49.6 \%$ response rate, the overall prevalence of VC was estimated to be $41 \%$. The primary reason for VC was to support the department chair and responsibilities included faculty mentorship, development, and evaluations. Fifty-five per cent of those without VC stated the position was not perceived as needed. Conclusion: VC are not widely utilised by pharmacy schools. For institutions considering VC, they may help offset the department chair's workload.
\end{abstract}

\section{Introduction}

The number of Colleges and Schools of Pharmacy in the United States (US) has nearly doubled from 72 programmes in 1978 (Barker, 2015) to 143 in 2019 (American Association of Colleges of Pharmacy, 2019). Significant growth of department chairs and faculty members is needed to support these new programmes. According to the American Association of Colleges of Pharmacy (AACP), there were 166 first-time faculty members during the 2019-2020 academic year (American Association of Colleges of Pharmacy, 2020). Junior faculty often require mentorship and guidance necessitating more time from department chairs. Assisting with faculty needs is just one of the many responsibilities of chairs which may also include teaching, programme planning, managing budgets, writing reports, and managing departmental space (laboratories, offices, and classrooms) (Schwinghammer et al., 2012).
The challenges facing department chairs in pharmacy education are complex and include increasing expectations on multiple levels. Some of these challenges are interpersonal issues with faculty or administration, time management, and financial concerns (Schwinghammer et al., 2012). It has been reported that department chairs in academic pharmacy work a median of 55 hours per week, with personnel management/development requiring a significant amount of their time (Schwinghammer et al., 2012). As a result, schools and colleges of pharmacy may need to find strategies to help offset the workload of department chairs.

In academic medical departments, the position of ViceChairs for Education (VCEd) has been used to manage departments. Brownfield and colleagues described the expectations of vice chairs for education to include "playing a supporting role for individual faculty involved in education," "provide mentoring and faculty development," and "ensure succession planning with faculty and staff" (Brownfield et al., 2012). The 
activities, roles, and responsibilities of VCEd have been reported for various medical specialities such as psychiatry (Cowley et al., 2018), surgery (Sanfey et al.,2012), and radiology (Lewis et al., 2015). In contrast, the authors of this report are unaware of similar published articles in the pharmacy literature; and therefore, little is known about such positions in academic pharmacy.

With the expansion of Schools and Colleges of Pharmacy, along with the growing number of deans who are approaching retirement age, there is a need to develop the pipeline for future administrators (Van Amburgh et al., 2010). In a 2012 study surveying pharmacy faculty aged 55 years and older, the average projected retirement age was 66.6 years (Latif et al., 2010). The AACP 2019-20 profile of pharmacy faculty shows that $45.7 \%$ of deans are aged 60 years or older, indicating many may be retiring in the near future (American Association of Colleges of Pharmacy, 2019). Developing future chairs from within a department may lead to less recruitment costs and a shorter and smoother transition period due to having an individual that already fits the culture of the institution (Fuentes, 2020). Succession planning can facilitate leadership transition (Rayburn et al., 2016). AACP, however, does not currently collect or publish data on vice chairs in their profile of pharmacy faculty (American Association of Colleges of Pharmacy, 2020) and therefore, it is unclear how many schools or colleges of pharmacy may utilise vice chairs for possible succession planning or otherwise. Therefore, the purpose of this pilot study was to determine the prevalence of Vice chairs in the United States pharmacy education. Additionally, this pilot study aims to describe and compare the roles and responsibilities of vice chairs in the Department of Pharmacy Practice (DPP), Department of Pharmaceutical Sciences (DPS), and Department of Social and Administrative Sciences (SAS). Moreover, researchers sought to determine why some institutions choose not to have such a position and the potential benefits for Vice chairs in succession planning. The results of this pilot study may increase awareness of the Vice chair position and provide guidance for a more formal survey.

\section{Methods}

Study researchers developed an anonymous and confidential survey for all Deans of Colleges and Schools of Pharmacy in the United States. The survey collected demographic information of vice chairs (age, gender, race/ethnicity, department, years in academia, and academic rank), institutional data (school representing, school accreditation status), roles and responsibilities of vice chairs, and reasons for having or not having a vice chair position. The survey was designed to be ten minutes in length. Multiple-choice and four-point Likert scale questions were included. Open-ended free-text responses were allowed for select questions. The survey was validated on face and content by study authors and was further reviewed by non-Dean administrators at one study author's institution.

Contact information for all United States Deans of Schools and Colleges of Pharmacy was obtained from the Accreditation Council of Pharmacy Education (ACPE) website. Deans $(n=145)$ were emailed the survey from October 2018 to November 2018 and were sent up to four additional email reminders every two weeks to complete the survey. In order to more accurately estimate the prevalence of vice chairs in Schools and Colleges of Pharmacy, study authors subsequently reviewed the websites of non-responding institutions (Figure 1). Data from the post-hoc analysis was only used to estimate the overall prevalence of vice chairs.

The study protocol was reviewed by the Institutional Review Board of Western University of Health Sciences and was determined to be exempt. Letters of reliance were used for Marshall B. Ketchum University College of Pharmacy and Keck Graduate Institute School of Pharmacy and Health Sciences. Informed consent was obtained through the survey invitation and in the introduction to the survey. Responses were analysed using qualitative and quantitative methods with Qualtrics software (Versions October 2018 - August 2020) and Microsoft Excel for Microsoft 365 MSO (Version 16.0.13231.20372). Descriptive statistics (mean with standard deviation, frequency, and percentages) were used to analyse and report survey data. Free text responses were evaluated by study authors for trends.

\section{Results}

Seventy-two surveys were returned for an overall response rate of $49.6 \%$. One respondent did not answer the question as to whether or not their school had a vice chair and thus was excluded from the analysis. Of the remaining 71 survey respondents, 46 indicated that they currently have a vice chair (64.8\%). From the post-hoc analysis, an additional 13 schools were found to have one or more vice chairs (Figure 1). Therefore, the overall prevalence of vice chairs in all US Colleges and Schools of Pharmacy based on survey respondents and the posthoc analysis website review was estimated to be $40.7 \%$. Eighty-nine per cent of all programmes that responded were accredited and most of the survey respondents were from the West Coast, East Coast and Midwest (Figure 2). 


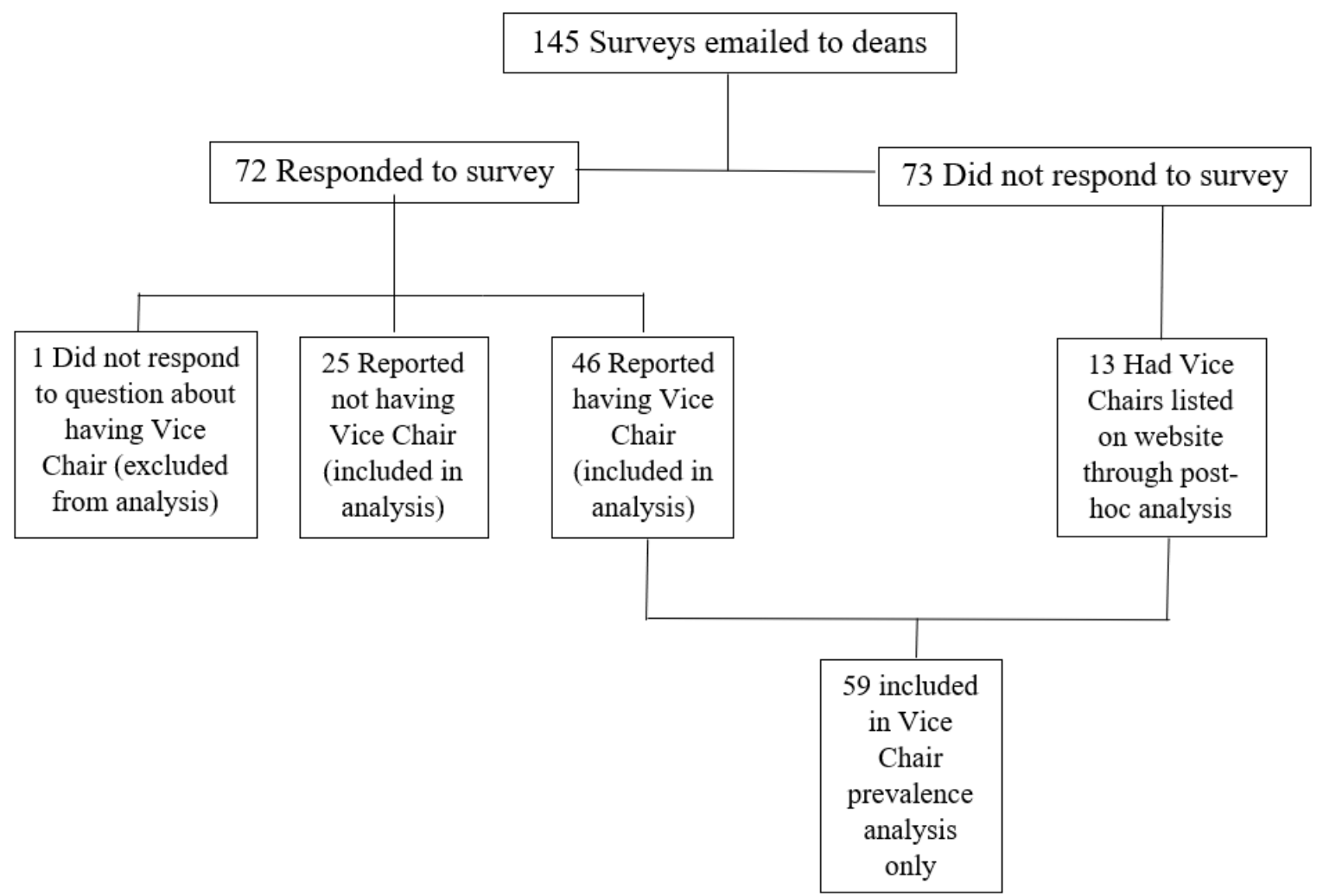

Figure 1: Survey respondents and inclusion in analysis



Figure 2: Map of Survey Respondents 
The average length the position has existed for across all departments was 7.5 years ( $S D=7.9$, range $<1$ month to 50 years) and was similar among the different departments: DPP 7.4 \pm 5.9 , DPS $8.7 \pm 11.7$, SAS $6.7 \pm 7.3$. Of the survey respondents with a vice chair, $41 \%(n=19)$ of Schools and Colleges had more than one vice chair, and $13 \%(n=6)$ had a vice chair in all three departments (DPP, DPS and SAS). Most Schools and Colleges had vice chairs in the DPP (60\%). The demographics of vice chairs of all respondents are listed in Table I. The majority of vice chairs in DPP and SAS were female $(56 \%$ and $83 \%$, respectively), Caucasian/non-Hispanic (75\% and $50 \%$, respectively), and aged $40-49$ (39\% and 50\%, respectively); compared to the majority of vice chairs in DPS who were male (44\%), Caucasian/non-Hispanic $(71 \%)$ and aged $50-69$ (47\%). The majority of vice chairs were also at the associate professor rank (DPP 53\%, DPS 53\%, SAS 50\%).

Table I: Demographics of vice chairs

\begin{tabular}{|c|c|c|c|c|}
\hline \multirow[b]{2}{*}{ Demographics } & \multicolumn{4}{|c|}{ Department } \\
\hline & DPP & DPS & SAS & All Department combined \\
\hline Vice chairs $n(\%)$ & $36(100)$ & $17(100)$ & $6(100)$ & $59(100)$ \\
\hline \multicolumn{5}{|l|}{ Gender n(\%) } \\
\hline Female & $20(56)$ & $5(29)$ & $5(83)$ & $30(51)$ \\
\hline Male & $16(44)$ & $11(65)$ & $1(17)$ & $28(47)$ \\
\hline Declined to state & $0(0)$ & $1(6)$ & $0(0)$ & $1(2)$ \\
\hline \multicolumn{5}{|l|}{ Age $n(\%)$} \\
\hline Under 30 & $2(6)$ & $0(0)$ & $0(0)$ & $2(3)$ \\
\hline $30-39$ & $11(31)$ & $1(6)$ & $2(33)$ & $14(24)$ \\
\hline $40-49$ & $14(39)$ & $7(41)$ & $3(50)$ & $24(41)$ \\
\hline $50-69$ & $7(19)$ & $8(47)$ & $1(17)$ & $16(27)$ \\
\hline Declined to state & $2(6)$ & $1(6)$ & $0(0)$ & $3(5)$ \\
\hline \multicolumn{5}{|l|}{ Race/Ethicity n(\%) } \\
\hline Caucasian/non-Hispanic & $27(75)$ & $12(71)$ & $3(50)$ & $42(71)$ \\
\hline Hispanic or Latino/a & $1(3)$ & $1(6)$ & $1(17)$ & $3(5)$ \\
\hline Black or African American & $1(3)$ & $1(6)$ & $0(0)$ & $2(3)$ \\
\hline Asian or Pacific Islander & $3(9)$ & $1(6)$ & $1(17)$ & $5(8)$ \\
\hline Declined to state & $4(11)$ & $2(12)$ & $1(17)$ & $7(12)$ \\
\hline \multicolumn{5}{|l|}{ Years in Academia n(\%) } \\
\hline $2-5$ years & $3(8)$ & $0(0)$ & $1(17)$ & $4(7)$ \\
\hline $6-10$ years & $11(31)$ & $2(12)$ & $3(50)$ & $16(27)$ \\
\hline $11-15$ years & $13(36)$ & $5(29)$ & $1(17)$ & $19(32)$ \\
\hline $16-20$ years & $3(8)$ & $5(29)$ & $0(0)$ & $8(14)$ \\
\hline$>20$ years & $6(17)$ & $5(29)$ & $1(17)$ & $12(20)$ \\
\hline \multicolumn{5}{|l|}{ Academic Rank n(\%) } \\
\hline Instructor & $1(3)$ & $0(0)$ & $0(0)$ & $1(2)$ \\
\hline Assistant Professor & $3(8)$ & $0(0)$ & $1(17)$ & $4(7)$ \\
\hline Associate Professor & $19(53)$ & $9(53)$ & $3(50)$ & $31(53)$ \\
\hline Full Professor & $13(36)$ & $8(47)$ & $2(33)$ & $23(39)$ \\
\hline
\end{tabular}

Note: DPP: Department of Pharmacy Practice; DPS: Department of Pharmaceutical Sciences; SAS: Department of Social and Administrative Sciences

The results from a multiple-choice question revealed the primary reasons for having a vice chair was to help support the Department Chair's responsibilities (DPP $66 \%$, DPS $75 \%$, SAS $86 \%$ ) and to focus on specific departmental needs (DPP 29\%, DPS 25\%, SAS 14\%). Only two programmes stated the primary reason for having the vice chair was to help manage the size of the DPP. Figure 3 describes the most common responsibilities of vice chairs among the various departments as listed by respondents. Across all three departments, the main roles included faculty mentorship (DPP 34\%, DPS 37\%, SAS 33\%), faculty development (DPP 33\%, DPS 43\%, SAS 33\%) and faculty evaluations (DPP 18\%, DPS 20\%, SAS 22\%). Figure 4 illustrates the specific departmental needs that vice chairs assisted with and reveals the majority participate in faculty development (DPP 29\%, DPS 24\%, SAS 32\%), research/scholarship (DPP 19\%, DPS 28\%, SAS 32\%), 
and didactic teaching (DPP 21\%, DPS 45\% SAS 32\%). A sizable amount of Vice chairs in DPP also assist with clinical service (17\%) and experiential/precepting (14\%).

The primary reason that schools did not have a vice chair was that they felt the position was not needed (54.6\%) compared to only $14 \%$ that cited lack of funding. Other reasons for not having a vice chair included small department size (9\%) and lack of senior faculty (5\%). Figure 5 describes the primary reasons programmes without a vice chair would consider having the position. Eighteen per cent of those without a vice chair would consider such a position for succession planning or training of a future leader. An overwhelming $83 \%(n=19)$ of programmes without a vice chair either agreed or strongly agreed that all Department Chairs need to mentor a future replacement.

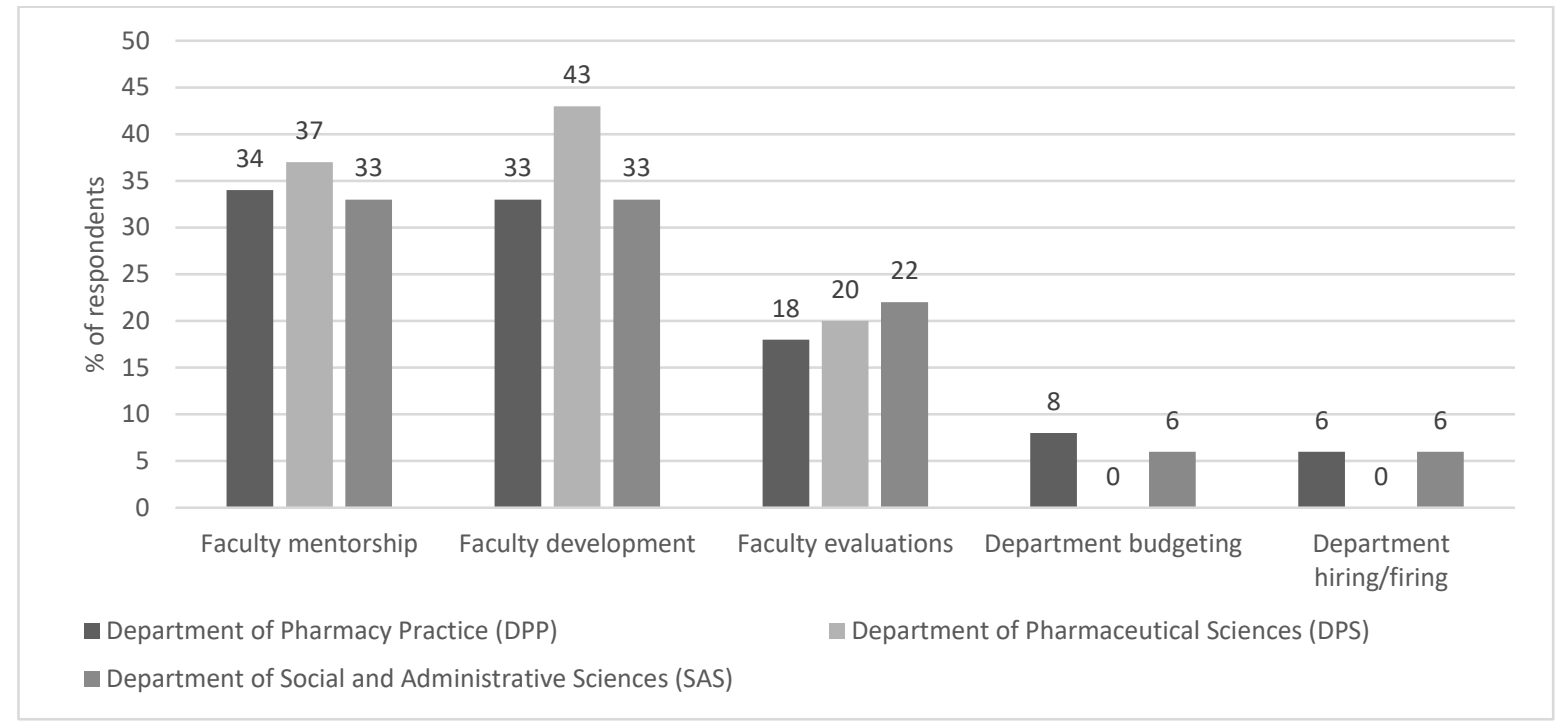

Question: For each department in which your school has a vice chair, please mark their responsibilities within that department. (Select all that apply) $(\mathrm{n}=40)^{*}$; *No data available for six respondents

Figure 3: Most common responsibilities of vice chairs listed by respondents

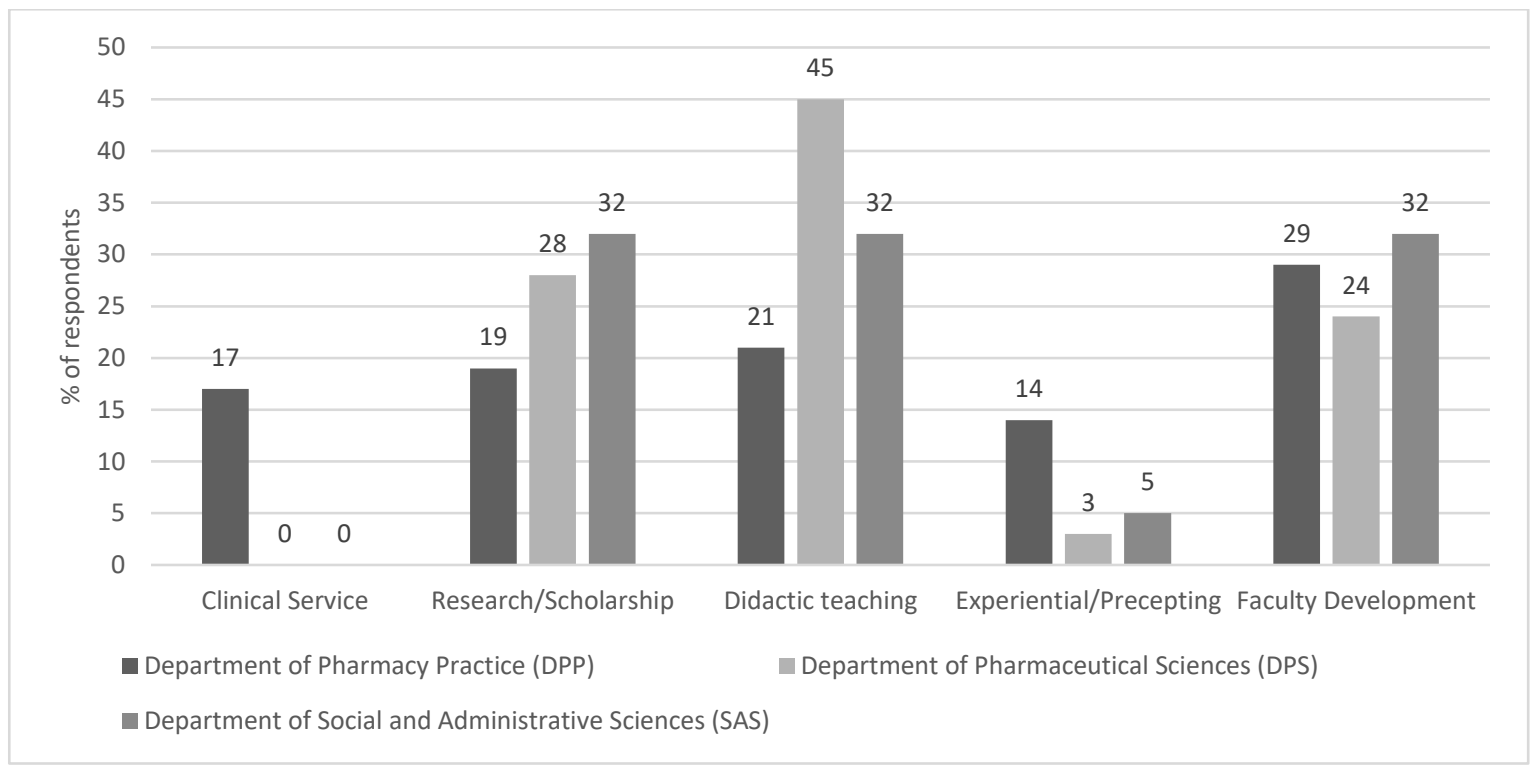

Question: For each department in which your school has a vice chair, please mark the specific need(s) your vice chair assists other faculty within their department. (Select all that apply) $(n=40) *$; ${ }^{*}$ No data available for six respondents

Figure 4: Specific departmental needs that vice chairs assisted within their department 


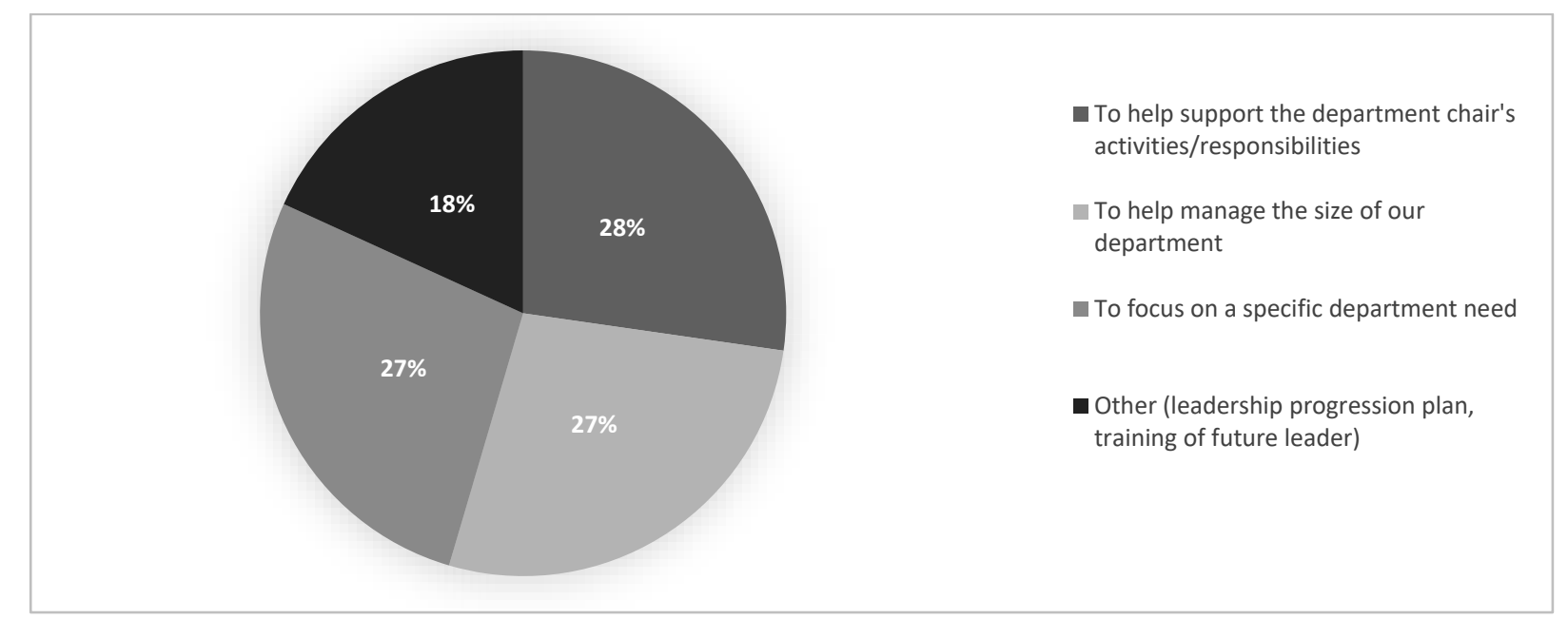

Question: If your school were to have a vice chair, the primary reason for that position would be: $(\mathrm{n}=22)^{*}$; *No data available for three respondents

Figure 5: Primary reasons programmes without a vice chair would consider having a vice chair position

\section{Discussion}

This is the first pilot study of its kind to estimate the prevalence and roles of vice chairs in academic pharmacy. Surprisingly, several programmes (41\%) had more than one vice chair, indicating that vice chairs can be utilised in all departments (DPP, DPS, and SAS). A previous study in academic medicine revealed a vice chair prevalence of $72 \%$ (Brownfield et al., 2012), whereas the present study showed a $41 \%$ prevalence for academic pharmacy. This discrepancy may be due to the relatively new existence of these positions and smaller department sizes for academic pharmacy departments (Collins, 2009; Brownfield et al., 2012). DPS had the highest average length of the vice chair position among the departments suggesting this department may have the most experience utilising vice chairs. Interestingly, department size may also be a contributing factor for programmes when considering a vice chair position as $27 \%$ of respondents without a vice chair stated that the need for help in managing the size of the department would be their primary reason for having one (Figure 5). In contrast, supporting the Department Chair's responsibilities was a higher priority than managing department size for respondents that had a vice chair. Future research may consider evaluating department size in relation to the utilisation of the vice chair position.

When compared to studies of vice chairs in medical education, this study showed similar responsibilities for vice chairs in academic pharmacy, namely faculty development, mentorship, and evaluations (Brownfield et al., 2012; Sanfey et al., 2012; Lewis et al., 2015; Cowley et al., 2018). Vice chair positions for pharmacy education were found to be utilised for a variety of departmental needs such as research/scholarship and didactic teaching (Figure 4). Not surprisingly, vice chairs in DPP also assisted with clinical service and experiential education and precepting, while most vice chairs in DPS and SAS did not. In contrast, some vice chairs in DPP and SAS had responsibilities related to department budgeting and hiring/firing, whereas DPS vice chairs did not (Figure 3 ).

According to the findings, $18 \%$ of programmes without vice chairs felt that the position could also assist with other departmental needs such as leadership progression planning and training of a future leader. As schools of pharmacy continue to expand and the demands for Department Chairs increase, vice chairs could establish a mentor-mentee like relationship from their Department Chair and help to offset their workload. Based on the AACP Profile of Pharmacy Faculty, 167 Deans, Associate Deans and Assistant Deans are aged 60 years and above, which could lead to large vacancies in administrative positions (American Association of Colleges of Pharmacy (2020). vice chairs could play a significant role in taking on administrative duties and possibly ease leadership transitions. As suggested in one report, strategic succession planning "has the potential to help organisations retain individuals, promote growth as an organisational value, and save costs in recruitment, onboarding, and orientation" (Fuentes, 2020). In this study, the majority of vice chairs were found to be at the associate professor rank or higher (52.5\%), which may help to better facilitate and contribute to faculty development and mentorship needs versus those at lower rank levels. By comparison, most of the vice chairs in medical education are at the professor rank (69\%) (Brownfield et al., 2012). 
Vice chairs who receive close mentoring from their Department Chairs may also be better positioned for career advancement. In the study by Plaza and colleagues, there was a significant correlation with pharmacy school deans that provided career-related mentorship for their protégés (Plaza et al., 2004). While this study looked at pharmacy deans, this may suggest that strengthening vice chair mentorship could possibly contribute to their growth as leaders throughout the pharmacy profession. As a result, future studies should consider exploring the mentorship of vice chairs to determine any effects on their leadership development and growth into higher administrative positions.

This work is not without its limitations. First, there may be a self-selection bias among Deans from schools with a vice chair position which may have accounted for the authors' response rate. The post-hoc analysis was therefore conducted to address this perceived selfselection bias to provide a more accurate account of the prevalence of vice chairs. However, using institutional websites to determine whether a vice chair position existed is limited by when the last update to the website was made. Therefore, the survey results may not accurately reflect the demographics, roles, and responsibilities of vice chairs across all institutions. Another limitation of this study could be non-response bias. However, the majority of non-respondents $(82.2 \%)$ were found not to have a vice chair from the post-hoc analysis; therefore, the impact on demographics, roles, and responsibilities may be minimal. The results for the survey question regarding the primary reason for schools not having a vice chair, however, could be skewed due to the non-response bias. Furthermore, there is the potential for variability in the interpretation and responses of all survey items. Some respondents also did not complete all survey items (Footnotes in Figures 3-5), so the data may not fully represent respondents. In addition, some survey items may not have adequately accounted for the possibility of multiple vice chairs at an institution or within a department, and most respondents were from the Midwest, East, and West Coast, which may not be fully representative of the United States. Lastly, the survey was not formally validated aside from face and content by study authors. However, the survey was also reviewed by non-Dean administrators at the study authors' institutions for formatting and clarity. Despite these limitations, the results of this pilot study could potentially be used to develop a formalised questionnaire to collect additional data such as salary information.

\section{Conclusion}

To the authors' knowledge, this is the first pilot study of its kind that has attempted to estimate the prevalence of vice chair positions within U.S. Schools and Colleges of Pharmacy and further describes their roles and responsibilities. Vice chairs appear to support the activities of their Department Chair, primarily in the areas of faculty mentorship and development. Vice chairs may also help to ensure continuity and stability in a department should the opportunity arise for them to transition into the Chair role as a means of succession planning. Vice chair positions should be clearly defined with specific roles and expectations to best serve the needs of the department. Since the vice chair position for pharmacy schools in this study have only existed for an average of 7.5 years, more time and research may be needed to evaluate the effectiveness and value of this position. Therefore, institutions may wish to consider the roles and responsibilities identified in this study if deciding to update an existing vice chair job description or to incorporate a new vice chair position. Additionally, since this is a pilot study, further larger studies will need to be conducted. Perhaps, AACP may consider collecting data on vice chairs for programmes to compare when considering adding a vice chair position.

\section{References}

American Association of Colleges of Pharmacy. (2019). Academic Pharmacy's Vital Statistics (Online). Available at: https://www.aacp.org/article/academic-pharmacys-vitalstatistics. Accessed 21 October 2020

American Association of Colleges of Pharmacy. (2020). 2019-20 Profile of Pharmacy Faculty (Online). Available at: https://www.aacp.org/system/files?file=2020-02/PPF1920final2. pdf\&Token=D2101F80-5A0A-4580-A99BA21CD15D5310

Accreditation Council of Pharmacy Education (ACPE) . (2021). Accreditation information for U.S. Schools and colleges of Pharmacy . Available at: www.acpe-accredit.org

Barker, A. (2015). The Pharmacy Job Crisis: Blame the Pharmacy School Bubble (Online). Pharmacy Times. Available at:

https://www.pharmacytimes.com/contributor/alex-barkerpharmd/2015/05/the-pharmacy-job-crisis-blame-thepharmacy-school-bubble

Brownfield, E., Clyburn, B., Santen, S., Heudebert, G., \& Hemmer, P.A. (2012). The activities and responsibilities of the vice chair for education in U.S. and Canadian departments of medicine. Academic Medicine, 87(8), 10411045. https://doi.org/10.1097/ACM.0b013e31825cf71a

Coleman, C.I., Schlesselmann, L., \& White, C.M. (2007). Journal publications by pharmacy practice faculty evaluated by institution and region of the United States (2001-2003). 
Pharmacy Practice, 5(4), 151-156.

https://doi.org/10.4321/s1886-36552007000400002

Collins S.K. (2009). Succession planning: perspectives of chief executive officers in U.S. hospitals. The health care manager, 28(3), 258-263.

https://doi.org/10.1097/HCM.0b013e3181b3eb0e

Cowley, D.S., Lehrmann, J.A., \& Dalack, G.W. (2018). The Role of the Vice Chair for Education in Departments of Psychiatry. Academic Psychiatry, 42(4), 482-488. https://doi.org/10.1007/s40596-017-0779-0

Fuentes D.G. (2020). Rethinking Approaches to Succession Planning and Developing a Leadership Pipeline in Academic Pharmacy. American Journal of Pharmaceutical Education, 84(12), 8335. https://doi.org/10.5688/ajpe8335

Latif, D.A., \& Alkhateeb, F.M. (2012). Pharmacy faculty retirement at colleges and schools of pharmacy in the United States and Canada. American Journal of

Pharmaceutical Education, 76(1), 4.

https://doi.org/10.5688/ajpe7614

Lewis, P.J., Probyn, L., McGuinness, G., Nguyen, J., Mullins, M.E., Resnik, C., \& Oldham, S. (2015). Developing a Job Description for a Vice Chair of Education in Radiology: The Advicer Template. Academic Radiology, 22(7), 933-938. https://doi.org/10.1016/j.acra.2015.02.001

Plaza, C.M., Draugalis, J.R., Skrepnek, G.H, Slack, M.S. (2004). The Role of Administrative Mentoring in the Pharmacy Deanship. American Journal of Pharmaceutical Education, 68(1-12). https://doi.org/10.5688/aj680486

Rayburn, W., Grigsby, K., \& Brubaker, L. (2016). The Strategic Value of Succession Planning for Department Chairs. Academic Medicine, 91(4), 465-468.

https://doi.org/10.1097/ACM.0000000000000990

Sanfey, H., Boehler, M., Darosa, D., \& Dunnington, G.L. (2012). Career development needs of vice chairs for education in departments of surgery. Journal of Surgical Education, 69(2), 156-161.

https://doi.org/10.1016/j.jsurg.2011.08.002

Schwinghammer, T.L., Rodriguez, T.E., Weinstein, G., Sorofman, B.A., Bosso, J.A., Kerr, R.A., \& Haden, N.K. (2012). AACP strategy for addressing the professional development needs of department chairs. American Journal of Pharmaceutical Education, 76(6), S7. https://doi.org/10.5688/ajpe766S7

Van Amburgh, J., Surratt, C.K., Green, J.S., Gallucci, R.M., Colbert, J., Zatopek, S.L., \& Blouin, R.A. (2010). Succession planning in U.S. pharmacy schools. American Journal of Pharmaceutical Education, 74(5), 86.

https://doi.org/10.5688/aj740586 